\title{
Enabling in vivo Photocatalytic Activation of Rapid Bioorthogonal Chemistry by Repurposing Si-Rhodamine Fluorophores as Cytocom- patible Far-Red Photocatalysts
}

\author{
Chuanqi Wang, ${ }^{1,+}$ He Zhang, ${ }^{2,+}$ Tao Zhang ${ }^{3}$, Xiaoyu Zou, ${ }^{2}$ Hui Wang, ${ }^{3}$ Julia Rosenberger, ${ }^{1}$ Raghu Van- \\ nam, ${ }^{1}$ William S. Trout, ${ }^{1}$ Xinqiao Jia,,${ }^{2,4^{*}}$ Zibo Li, ${ }^{3,}{ }^{*}$ Joseph M. Fox ${ }^{1,2,}{ }^{*}$ \\ ${ }^{1}$ Department of Chemistry and Biochemistry, University of Delaware, Newark, Delaware 19716, USA \\ ${ }^{2}$ Department of Materials Science and Engineering, University of Delaware, Newark, Delaware 19716, USA \\ ${ }^{3}$ Department of Radiology and Biomedical Research Imaging Center, University of North Carolina at Chapel \\ Hill, Chapel Hill, North Carolina 27599, USA \\ ${ }^{4}$ Delaware Biotechnology Institute, Newark, Delaware 19711, USA
}

\begin{abstract}
Chromophores that absorb in the tissue-penetrant far-red/near-infrared window have long served as photocatalysts for the generation of singlet oxygen for photodynamic therapy. However, the cytotoxicity and side-reactions associated with singlet oxygen sensitization have posed a problem for using long wavelength photocatalysis to initiate other types of chemical reactions in biological environments. Described here is the use of Si-Rhodamine (SiR) dyes as photocatalysts for inducing rapid bioorthogonal chemistry using $660 \mathrm{~nm}$ light through the oxidation of a dihydrotetrazine to a tetrazine in the presence of trans-cyclooctene dienophiles. SiRs have been commonly used as fluorophores for applications in biology, but have not previously been applied to catalyze chemical reactions. A dihydrotetrazine/tetrazine pair is described that displays high stability in both oxidation states. A series of SiR derivatives were evaluated, and the Janelia-SiR dyes were found to be especially effective in catalyzing rapid photooxidation at low catalyst loadings (typically $1 \mu \mathrm{M}$ ). A protein that was site-selectively modified by trans-cyclooctene was quantitively conjugated upon exposure to $660 \mathrm{~nm}$ light and a dihydrotetrazine. By contrast, a previously described methylene blue catalyst was found to rapidly degrade the protein. SiR-red light photocatalysis was used to crosslink hyaluronic acid derivatives that were functionalized by dihydrotetrazine and trans-cyclooctenes, enabling 3D culture of human prostate cancer cells. This photoinducible hydrogel formation could also be carried out in vivo in live mice through subcutaneous injection of a solution containing SiR photocatalyst and a Cy7-labeled hydrogel precursor, followed by brief in vivo irradiation with $660 \mathrm{~nm}$ light to produce a stable hydrogel material. This cytocompatible method for using red light photocatalysis to activate bioorthogonal chemistry is anticipated to find broad applications where spatiotemporal control is needed in the in vivo environment.
\end{abstract}

\section{Introduction}

Photocatalysis has had a transformative impact on organic synthesis and holds promise as an enabling tool in chemical biology and medicine. ${ }^{1-4}$ To be useful for in vivo applications, it is generally necessary to initiate photochemistry in the far-red/ near-infrared (NIR) window spanning 650-900 nm. ${ }^{5}$ While $\mathrm{red} / \mathrm{NIR}$ light is not toxic and can penetrate tissue, low energy $(<45 \mathrm{kcal} / \mathrm{mol})$ limits the modes of reactivity that can be initiated by photons at these long wavelengths. ${ }^{5}$ Innovative strategies based on cyanine, ${ }^{6}$ BODIPY, ${ }^{7}$ and phthalocyanine ${ }^{8}$ dyes and $\mathrm{Ru}$-complexes ${ }^{9}$ have been used to initiate decaging with $\mathrm{red} / \mathrm{NIR}$ light. In addition to these stoichiometric processes, NIR dyes have served as photocatalysts in Photodynamic Therapy (PDT), where $\mathrm{O}_{2}$ and light are used to produce singlet oxygen, which causes oxidative damage and ultimately leads to cell death. ${ }^{10}$ While photocatalytically generated singlet oxygen can be used to promote selected in vivo reactions, ${ }^{11}$ for many applications the cytotoxicity and side-reactions associated with singlet oxygen sensitization poses challenges for using long wavelength photocatalysis to initiate many types of chemical reactions in biological environments.

Over the past two decades, bioorthogonal chemistry has been used for a broad array of applications spanning biomedicine and biotechnology. ${ }^{12,13}$ A range of non-natural reactions can now be carried out routinely in live cells under in vitro or in vivo conditions not only for bioconjugation but also in deconjugative bioorthogonal reactions that enable cargo delivery. ${ }^{14-22}$ Significant in this field has been the development of photoinducible bioorthogonal reactions as methods for turning on bioorthogonal reactions with spatial resolution and temporal control. ${ }^{23,24}$ Important advances include photochemical reactions of tetrazoles $^{25-27}$ and cyclopropenone ${ }^{28-31}$ derivatives to produce reactive nitrile imines and cyclooctyne derivatives, respectively. Other advances include photo-induced versions of the Staudinger $^{32}$ and $\mathrm{CuAAC}^{33}$ reactions as well as cycloadditions involving azirines ${ }^{34}$ benzyne ${ }^{35}$, diarylsydnones,${ }^{36,37}$ quinones, ${ }^{38-}$ 41 o-napthaquinone methides ${ }^{42}$, o-quinodimethanes ${ }^{43,44}$ and trans-cycloheptene. ${ }^{45}$ While several methods for initiating bioorthogonal chemistry using NIR light with two-photon excitation have been described, ${ }^{29,46}$ prior to our work, the direct use of red/NIR light to induce bioorthogonal reactivity had not been described. ${ }^{47}$

The bioorthogonal Diels-Alder reactions of tetrazines with strained alkene and alkyne dienophiles has become increasingly important to the chemical biology community due to their exceptional kinetics with rates that can exceed $10^{6} \mathrm{M}^{-1} \mathrm{~s}^{-1}$ with conformationally strained trans-cyclooctenes. ${ }^{48-51}$ Recent interest in the development of photochemically inducible variants of 
tetrazine ligation have prompted the discovery of new methods for uncaging cyclopropene ${ }^{52,53}$ and bicyclononyne ${ }^{28}$ dienophiles. Tetrazine (Tz) synthesis is commonly achieved through the oxidation of dihydrotetrazine (DHTz) precursors, ${ }^{54}$ and the DHTz/Tz redox couple has been used in electrochemically controlled bioconjugation at electrode surfaces, ${ }^{55}$ in batteries, ${ }^{56}$ and for colorimetric nitrous gas detection. ${ }^{57}$ In preprint, an o-nitrophenylphenyl protected dihydrotetrazine has been used with $405 \mathrm{~nm}$ light and without catalysis to uncage tetrazines that react with TCO with rates of $10^{2} \mathrm{M}^{-1} \mathrm{~s}^{-1} .58$

An area of interest has been the development of hydrogel materials for disease modeling in vitro and cell delivery to specific anatomical locations in vivo. ${ }^{59-61}$ In addition to physical crosslinking through non-covalent interactions, ${ }^{62}$ gelation through covalent bond formation has been achieved via reactions including Michael additions ${ }^{63}$, click chemistry ${ }^{64}$ and photo-initiated crosslinking processes. ${ }^{65}$ Photo-initiated methods of hydrogelation offer the additional benefit of precise spatial and temporal control. For in vivo applications, methods based on long wavelength light ${ }^{66,67}$ are desirable to enable deep tissue penetration. Such methods may extend to materials for regenerative medicine ${ }^{68}$ and for in vivo disease modeling. ${ }^{69,70}$ Injectable materials that can form 3D hydrogels have the potential for creating better cancer xenograft models for the study of cancer biology. For example, LNCaP prostate cancer cells are poorly tumorigenic and generally require other types of cells or Matrigel to support tumor model generation ${ }^{71,72}$. Two-photon methods provide an approach for hydrogel patterning with high spatial resolution using far-red/NIR light. However, the very small focal volumes of two-photon techniques can limit their biomedical applications, and the development of chemical methods that directly utilize far-red/NIR light would be desirable. ${ }^{73}$

Previously, our group described a method for catalytic turnon of the tetrazine ligation, where rapid bioorthogonal reactivity can be induced by controllable, catalytic stimuli. ${ }^{47}$ Either visible light and a photosensitizer or very low loadings of horseradish peroxidase can be used to catalyze the oxidation of a dihydrotetrazine to a tetrazine with oxygen as the terminal oxidant (Fig 1). Several photocatalysts were found to be effective including methylene blue, which catalyzes photooxidation with excitation by $660 \mathrm{~nm}$ light.

Our initial system for photocatalytic oxidation has found several applications, ${ }^{74-76}$ including the activation of polymeric fibers for protein conjugation purposes.$^{47}$ However, our attempts to apply photocatalysis in live cell environments were limited by issues of phototoxicity, presumably because methylene blue is also a strong sensitizer for singlet oxygen.

We queried whether far-red fluorescent dyes that are commonly used for applications in biology might find additional purpose as photocatalysts for inducing rapid bioorthogonal chemistry. Herein, we describe a mild, photocatalytic system for DHTz oxidation using Si-Rhodamine (SiR) derivatives 1, which are water soluble and absorb in the far-red range. While SiR dyes have previously been utilized as fluorophores for cellular and in vivo imaging ${ }^{77-80}$ and as fluorogenic probes for detecting singlet oxygen, ${ }^{81}$ they have not been used as photocatalysts. Here, we show that SiR derivatives efficiently and rapidly catalyze the oxidation of DHTz derivatives with greatly enhanced compatibility toward trans-cyclooctene dienophiles while also displaying enhanced cytocompatibility.

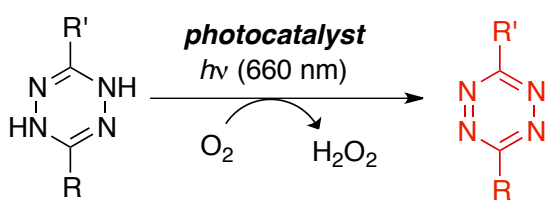

OFF

ON
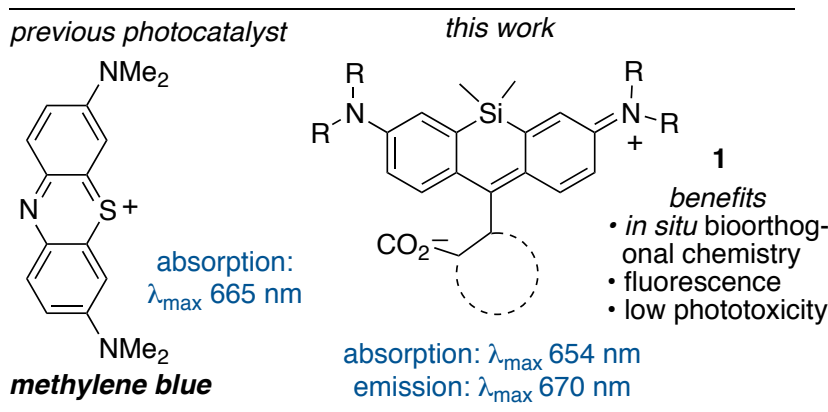

Fig 1. Photocatalytic oxidation of dihydrotetrazines with far-red light.

\section{Results and Discussion}

Previously, we showed that the DHTz 2 (Fig 2A) could be oxidized to its corresponding $\mathrm{Tz} \mathbf{3}$ under the action of photocatalysis or oxidation by HRP. While DHTz 2 was highly resilient toward background oxidation in organic solvents, in PBS buffer the background oxidation of $\mathbf{2}$ to tetrazine $\mathbf{3}$ proceeded at a rate of $\sim 3 \%$ conversion $/ \mathrm{h}$ in PBS in the dark. ${ }^{47}$ In ambient light, the rate of background oxidation was even faster. We sought to develop a more stable DHTz. Anticipating that a DHTz with an ortho-substituted aromatic group would be less susceptible to background oxidation, DHTz $\mathbf{4}$ and derivatives $\mathbf{5}$ and $\mathbf{6}$ were synthesized from 2-cyano-3-fluoropyridine via the route outlined in Fig 2B. The stability of water-soluble derivative $\mathbf{6}$ was studied by UV-Vis spectroscopy, and was found to be $95 \%$ stable after standing for 24 hours in metal-free PBS-buffer. ${ }^{82}$ Relative to 2, Compound $\mathbf{6}$ also showed much improved stability in PBS containing $10 \%$ mouse serum, with $80 \%$ of 6 retained in the DHTz oxidation state after $24 \mathrm{~h}$ (Fig S7). Once oxidized, the stability of $\mathrm{Tz} 7$ was similar to that of previously reported tetrazine 3 , with $80 \%$ of the tetrazine remaining after incubation for 24 hours in PBS at room temperature (Fig 2D). In DielsAlder chemistry, tetrazine 3 also displayed rapid kinetics with a second-rate constant of $56,000 \pm 190 \mathrm{M}^{-1} \mathrm{~s}^{-1}$ toward axial-5hydroxy-trans-cyclooctene (Fig S8-9) that is nearly as rapid as the analogous reaction of $\mathbf{3}\left(80,200 \pm 1700 \mathrm{M}^{-1} \mathrm{~s}^{-1}\right.$, Fig S10,11).

Our initial studies revealed the incompatibility of methylene blue (MB) photocatalysis with trans-cyclooctene dienophiles. Photocatalysis was used to oxidize DHTz 6 to Tz 7 (Fig 3A). Low concentrations of $\mathrm{MB}(1 \mu \mathrm{M})$ converted $35 \mu \mathrm{M} 6$ to 7 upon irradiation with $660 \mathrm{~nm}$ light within $1.5 \mathrm{~min}$. Reactions were monitored in situ using UV-Vis spectroscopy, which showed DHTz 6 was formed in quantitative yield. Starting material $\mathbf{6}$ and product 7 have absorption maxima at 354 and $417 \mathrm{~nm}$, respectively, and the spectra have an isobestic point at $367 \mathrm{~nm}$ (Fig 3B). However, attempts to carry out the oxidation of 6 in 
A. Previous $D H T z / T z$ system
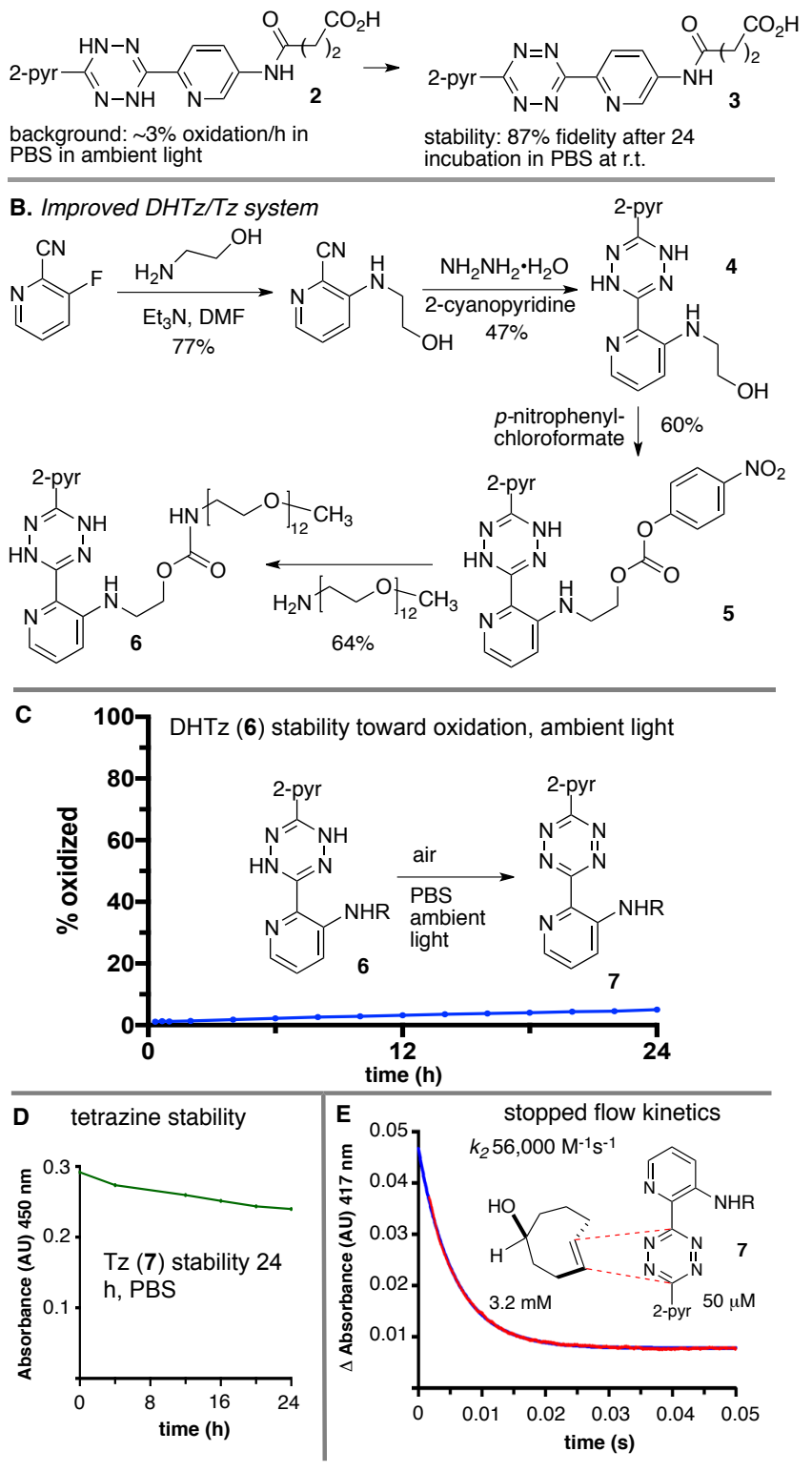

Fig 2. (A) Previous DHTz/Tz redox pair used for catalytic oxidation chemistry. (B) Synthesis of a DHTz with improved stability in both the reduced and oxidized states. $(\mathbf{C}, \mathbf{D})$ Stability data in PBS, air and ambient light for (C) DHTz 6 and (D) Tz 7 as monitored by tracking $\mathrm{UV}-\mathrm{V}$ is absorption at $354 \mathrm{~nm}$ for $\mathbf{6}$ and by $450 \mathrm{~nm}$ for 7. (E) Stopped flow kinetics with UV-monitoring was used to measure the rate of tetrazine ligation. Data is plotted in red and the kinetic fit is in blue.

the presence of TCO derivatives was marked by kinetically complex behavior, with the observation of a significant induction period prior to the consumption of $\mathbf{6}$. Moreover, a major limitation of the methylene blue system for photoactivation was revealed by irradiation of a solution of the $12-\mathrm{kDa}$ protein thioredoxin (Trx) in the presence of methylene blue. As shown in Fig 3C, after 4 min far-red-light irradiation, the protein without MB still ionizes efficiently by HRMS with signal/noise $(\mathrm{S} / \mathrm{N})$ $>100$. However, with the presence of MB $(1 \mu \mathrm{M})$, the mass spectral quality of Trx decreased dramatically with $\mathrm{S} / \mathrm{N}<10$. These results illustrate the challenges associated with methylene blue-based photocatalysis with biological molecules.
As shown in Fig 4, SiR dyes were identified as novel, effective photocatalysts for DHTz oxidation with $660 \mathrm{~nm}$ light. Investigated were the analogs of the parent SiR dye 1a-b and the azetidine analogs 1c-e developed by Lavis. ${ }^{80}$ These dyes have maxima ranging from 643-669 nm, and as shown in Fig 4A, all of these SiR dyes are effective photocatalysts. As shown in Fig $4 \mathrm{~B}$, the conversion of $\mathbf{6}$ to 7 was followed by in situ UV-Vis spectroscopy by monitoring the reduction of absorption at 354 $\mathrm{nm}, \lambda_{\max }$ for DHTz 6 . Conversion to product was light dependent, with complete conversion of $35 \mu \mathrm{M} 6$ to 7 in quantitative

Fig 3 (A) Catalytic oxidation of 6 to 7 with methylene blue (MB) photocatalysis. (B) UV-Vis spectroscopy was used to monitor reaction progress by following absorptions due to $6\left(\lambda_{\max } 354 \mathrm{~nm}\right)$ and $7\left(\lambda_{\max } 417 \mathrm{~nm}\right)$ relative to the isobestic point at $367 \mathrm{~nm}$. (C) Raw ESI mass spectra of the protein thioredoxin after 4 min irradiation with (top) and without (bottom) MB.
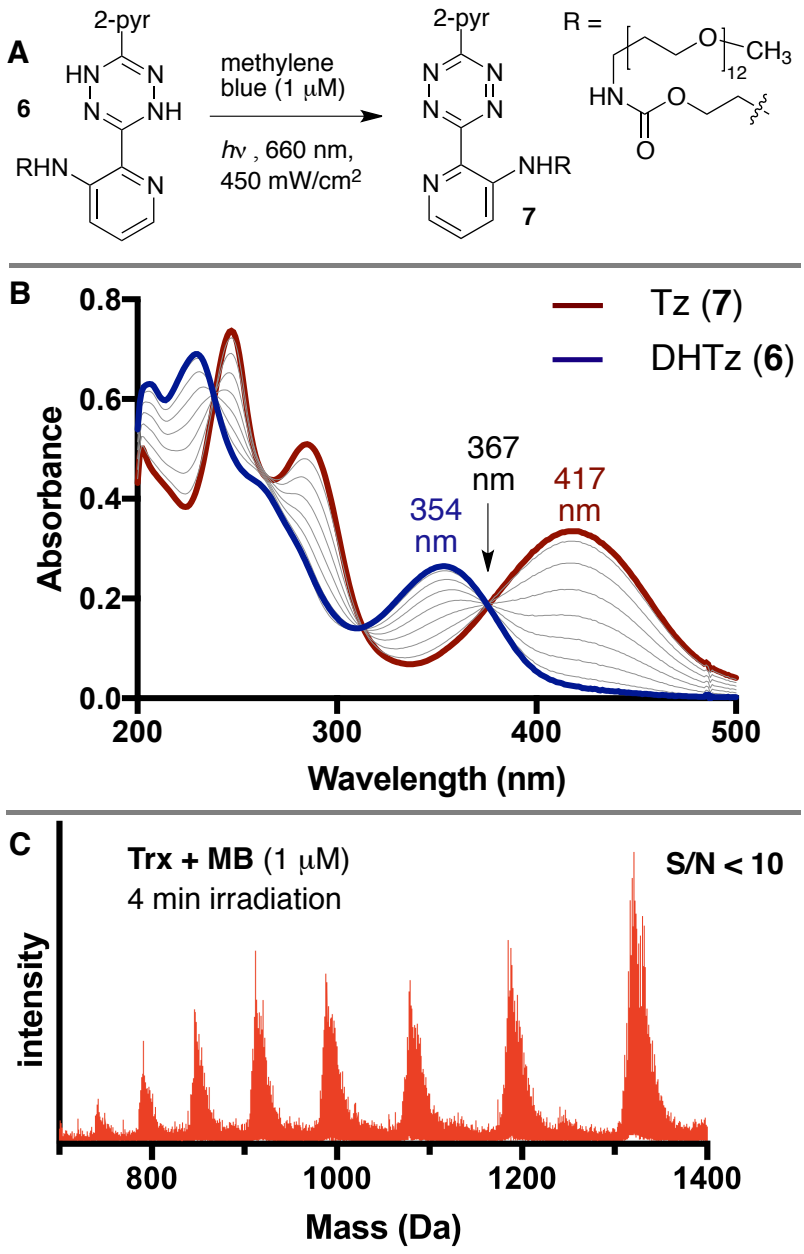

Trx without MB

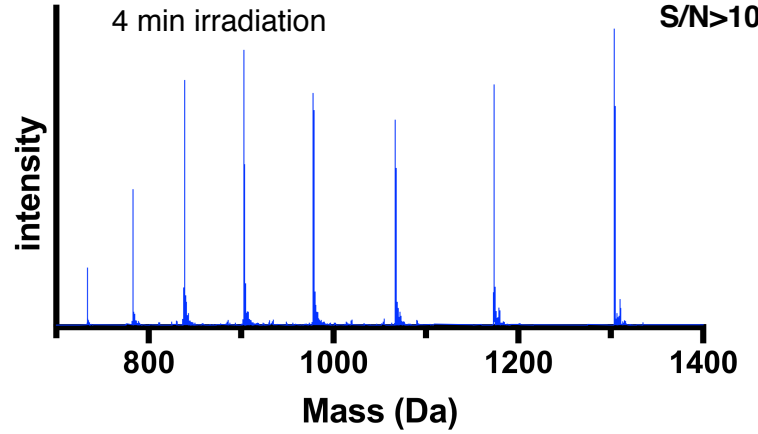


yield within 140 seconds when $1 \mu \mathrm{M}$ of catalyst $1 \mathrm{~d}$ was used. The rate of conversion of $\mathbf{6}$ was not influenced by the addition of superoxide dismutase $(1 \mu \mathrm{M})$ nor the singlet oxygen scavenger $^{83}$ methionine $(70 \mathrm{mM})$, suggesting that the mechanism of SiR-catalyzed DHTz oxidation occurs by a pathway that does involve intermediacy of superoxide or singlet oxygen, and instead involves direct sensitization of the DHTz by SiR, plausibly involving electron transfer to the excited state of $\mathrm{SiR}^{84,85}$

Fig 4. (A) Oxidation of DHTz 6 to 7 with SiR catalysts. (B) Oxidation of $\mathbf{6}$ to $\mathbf{7}$ catalyzed by $\mathbf{1 d}$ is light dependent, and independent of quenchers of superoxide (SOD) and ${ }^{1} \mathrm{O}_{2}$ (methionine). (C) Rates of oxidation by $\mathrm{MB}$ and $\mathrm{SiR}$ catalysts.
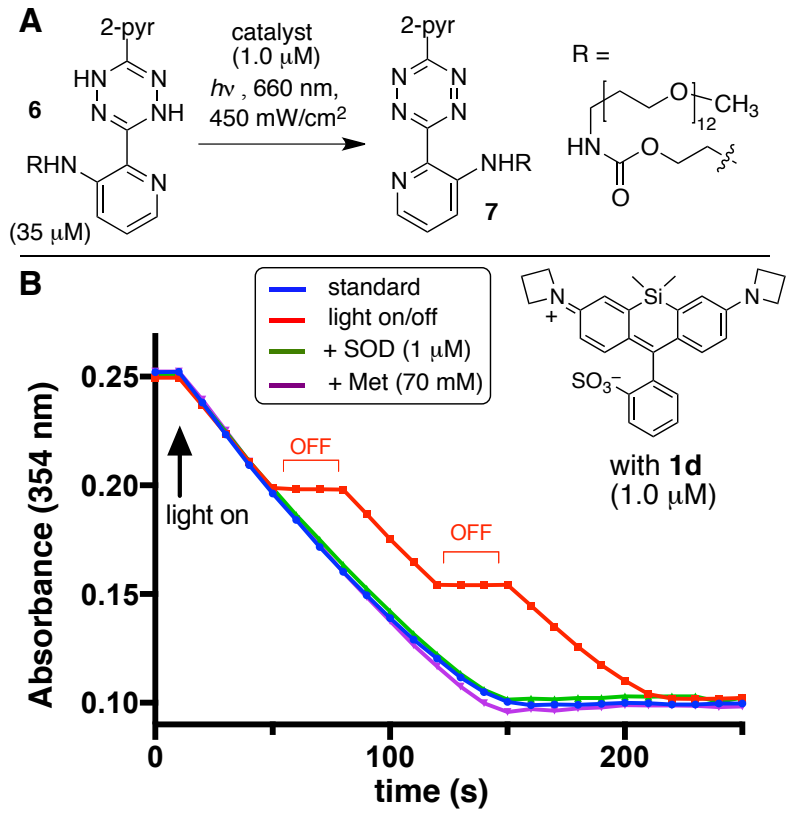

C times to completion with $500 \mathrm{nM} \mathbf{1 d}$ and $50 \mu \mathrm{M} 6$<smiles>CN(C)c1ccc2nc3ccc(N(C)C)cc3[s+]c2c1</smiles><smiles>C[Si]1(C)C2=CC(=[N+]3CCC3)C=CC2=C(Br)c2ccc(N3CCC3)cc21</smiles>

$\mathrm{MB}: 300 \mathrm{sec}$

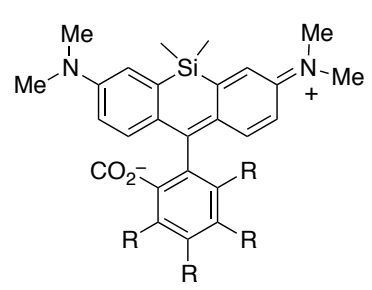

1a $(\mathrm{R}=\mathrm{H}) \quad$ 1b $(\mathrm{R}=\mathrm{F})$

$810 \mathrm{sec} \quad 650 \mathrm{sec}$<smiles>O=C(O[Na])c1cscc1N=[W]</smiles>
1d: $\mathrm{Ar}=$

$$
410 \mathrm{sec}
$$

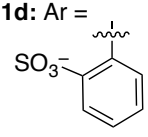

$450 \mathrm{~s}$<smiles>[18OH]c1c([18OH])c(F)c(F)c(F)c1F</smiles>

In a comparative study using $50 \mu \mathrm{M} 6$ and $500 \mathrm{nM}$ of photocatalyst, all of the SiR dyes 1a-e were effective photocatalysts that produced tetrazine 7 in $>95 \%$ yield as judged by $\mathrm{UV}-\mathrm{V}$ is spectroscopy in PBS (Fig 4C and S4). The fastest conversions were observed with the thiophene analog 1c and benzenesulfonate 1d, where completion was reached in 410 and $450 \mathrm{sec}$, respectively, approaching the rates observed with methylene blue catalysis ( $300 \mathrm{sec}$ ) under the same conditions.

The ability of SiR $\mathbf{1 d}$ to photocatalyze the oxidation of DHTz 6 with in situ protein conjugation was demonstrated as shown in Fig 5. A single cysteine mutant of the protein thioredoxin
A
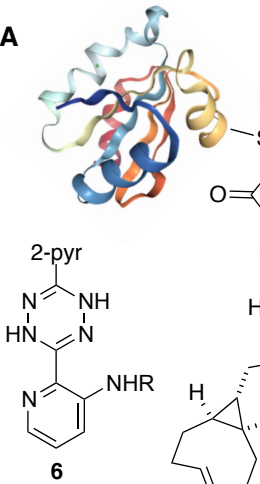

$0=\lambda_{N}^{S}$

$(25 \mu \mathrm{M})$

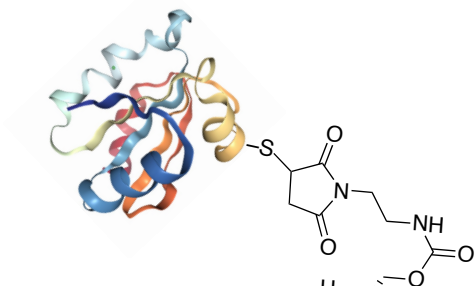

$\mathrm{O}$

$\sum_{\mathrm{HN}}$ 1) $h v, 660 \mathrm{~nm}$,

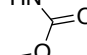

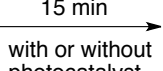

1d $(1 \mu \mathrm{M})$

2) chase
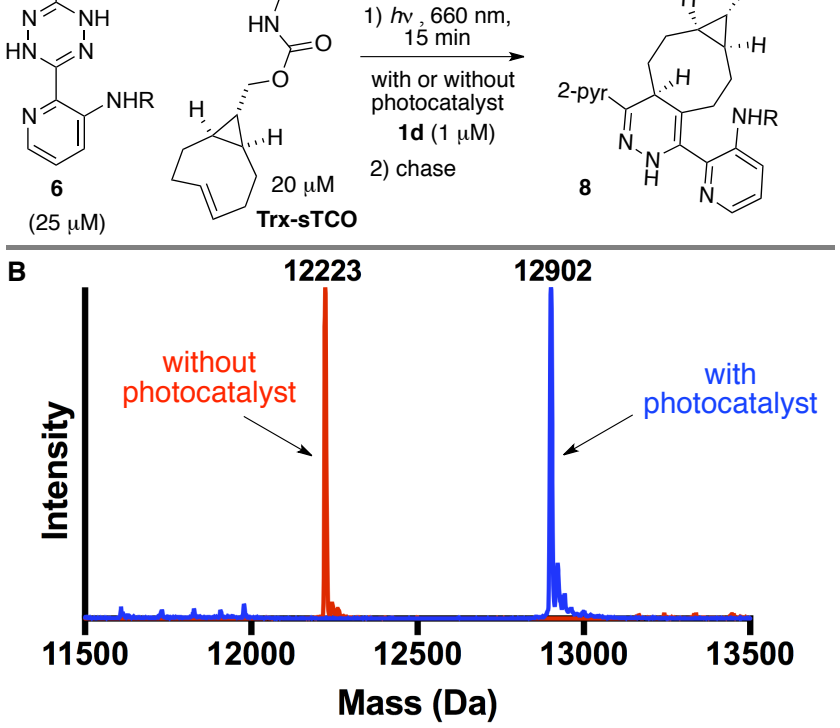

C

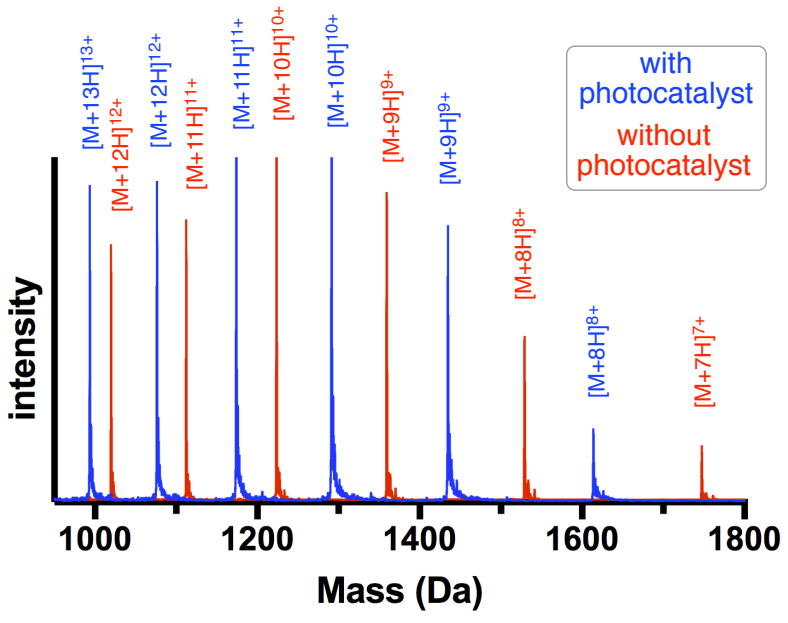

Fig 5. (A) Reaction of a thioredoxin-trans-cyclooctene conjugate (Trx-sTCO) with DHTz 6 proceeds efficiently in the presence of light and photocatalyst, but not if the catalyst or light is omitted. The reaction was carried out by exposing a solution of Trx-sTCO $(20 \mu \mathrm{M})$ and $6(25 \mu \mathrm{M})$ to $660 \mathrm{~nm}$ light and photocatalyst 1d $(1 \mu \mathrm{M})$ for $15 \mathrm{~min}$, followed by chasing with (4-(6-methyl-1,2,4,5-tetrazin-3-yl)phenyl)methanol to capture unreacted Trx-sTCO and MS analysis. (B) Deconvoluted and $(\mathbf{C})$ raw mass spectra for the combination of $\mathbf{6}$ with Trx-sTCO in the presence of catalyze 1d in the presence (blue) and absence (red) of $660 \mathrm{~nm}$ light. Product 8 is only formed in the pres-

(Trx-C32) was derivatized as the conjugate Trx-sTCO,${ }^{86}$ which does not react with DHTz 6 in the absence of light and/or photocatalyst. However, in the presence of $660 \mathrm{~nm}$ light and photocatalyst $1 \mathbf{d}(1 \mu \mathrm{M})$, in situ oxidation and Diels-Alder reaction proceeded efficiently to give conjugate $\mathbf{8}$ as determined by mass spectrometry (Fig 5B, C). As shown in Fig 5B, conversion to 8 was high, and as shown in Fig 5C, spectral quality was also high $(\mathrm{S} / \mathrm{N}>100)$ and did not suffer from singlet-oxygen mediated 
degradation that was evident when Trx was irradiated in the presence of methylene blue (Fig 3C).
Tetrazine ligation has been used for the creation of hydrogels for tissue engineering applications including in vivo cell delivery $^{87}$ and the creation of molecularly patterned matrices based
A

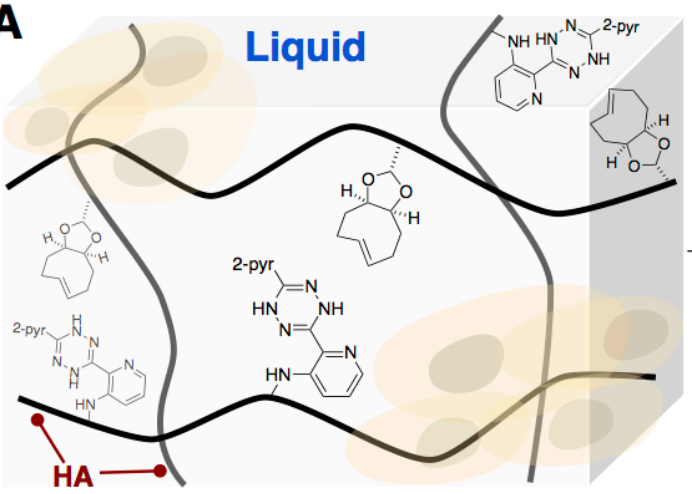

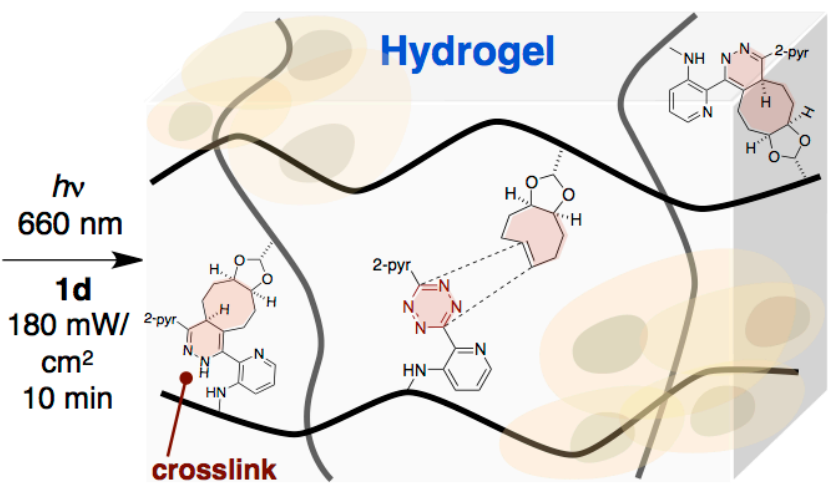

B

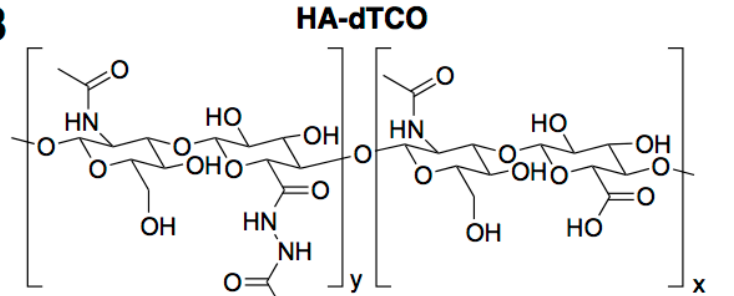

C
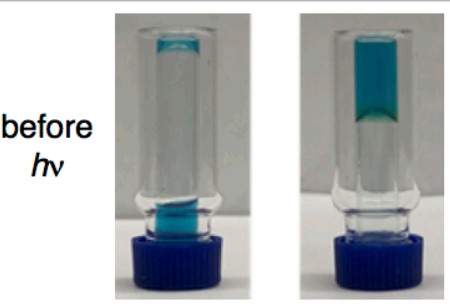

after

$h v$

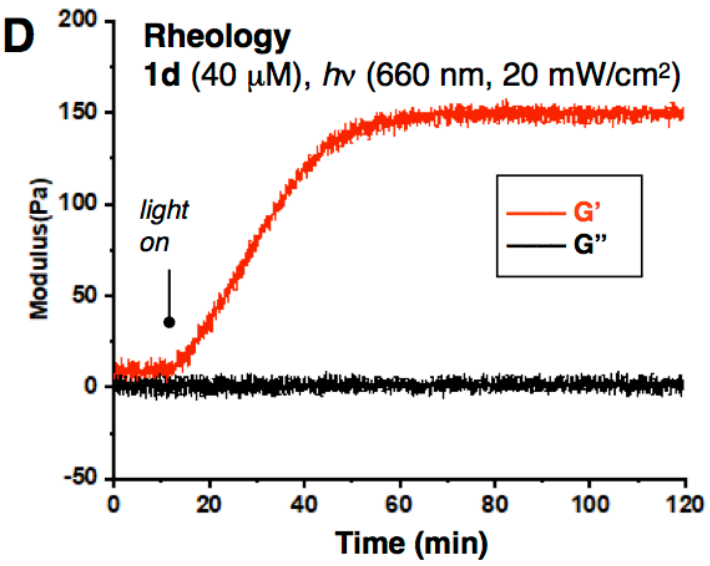

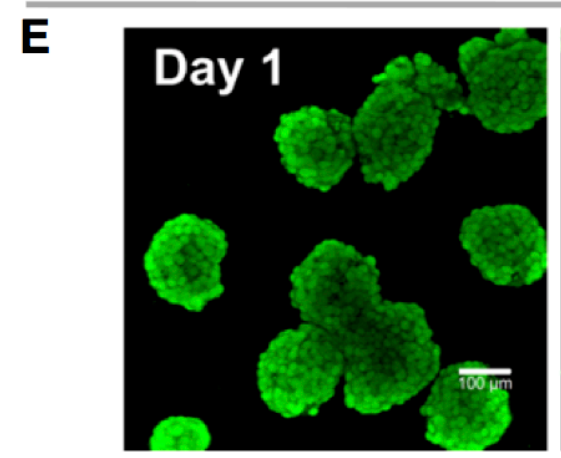
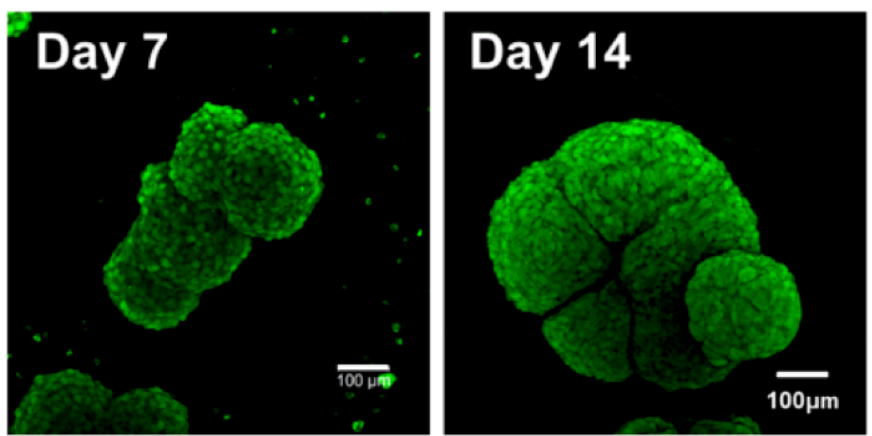

Fig 6. (A) Schematic description of red light photocatalytic turn-on of tetrazine ligation for cell encapsulation in HA hydrogels. (B) HA-dTCO $(2.5 \mathrm{mM})$ and HA-DHTz $(2 \mathrm{mM})$ were crosslinked by exposure to $660 \mathrm{~nm}$ light and catalyst $1 \mathrm{~d}(40 \mu \mathrm{M})$. (C) Vial inversion tests before and after irradiation indicating transformation of a liquid to a hydrogel. The blue color is due to the SiR dye. (D) Representative rheological measurements of HA hydrogels prepared with $660 \mathrm{~nm}$ irradiation and SiR. For rheology, longer irradiation was required due to the lower intensity light source. (E) Confocal microscopy images of LNCaP spheroids after 1,7 and 14 days of culture in HA hydrogels. Constructs were produced by irradiating a solution of HA-dTCO and HA-DHTz containing suspended cell spheroids. Live and dead cells were stained by calcein AM (green) and ethidium homodimer (red), respectively. No dead cells were observed by microscopy. 
on interfacial bioorthogonal chemistry. ${ }^{88}$ Previously, Truong, Forsythe and coworkers used our first generation system (catalytic methylene blue, DHTz 2, $660 \mathrm{~nm}$ light) via crosslinking with a 4-arm PEG-norbornene to encapsulate human mesenchymal stem cells (hMSCs); however, cell viability beyond Day 1 was not described. ${ }^{75}$ In our own experiments the phototoxicity of methylene blue and the sensitivity of DHTz 2 under cell culture conditions has limited the broader application of our first generation system for tissue engineering purposes.

As an illustration of the utility of SiR-photocatalyzed DHTz oxidation, we used catalyst $\mathbf{1 d}$ in conjunction with far-red light to catalyze the formation of hyaluronic acid (HA)-based hydrogel matrices for 3D cell culture from a liquid cellular suspension. HA is a natural polysaccharide that is widely used to create hydrogels with desirable properties for drug delivery and tissue engineering applications. ${ }^{89,90}$ As illustrated graphically in Fig $6 \mathrm{~A}$, we sought to initiate crosslinking of HA-derivatives bearing DHTz and TCO functionality upon irradiation at $660 \mathrm{~nm}$ in the presence of LNCaP prostate cancer spheroids using a SiRphotocatalyst. As shown in Fig 6B, dTCO and DHTz functionalized HA (HA-dTCO and HA-DHTz) were prepared using hydrazide linkers. Here, the dioxolane-fused dTCO was chosen due to its improved hydrophilicity relative to conventional TCO dienophiles. ${ }^{48}$ As shown in Fig 6C, the hydrogel precursor solution was free-flowing before irradiation. After $10 \mathrm{~min}$ irradiation at $660 \mathrm{~nm}\left(180 \mathrm{~mW} / \mathrm{cm}^{2}\right)$, a self-supporting hydrogel formed. Oscillatory rheology with in-situ irradiation was then used to confirm hydrogel formation of the pre-gel solution of a desired formulation. As shown in Fig 6C, the storage modulus $\left(G^{\prime}\right)$ increased noticeably upon the application of far-red light within $5 \mathrm{~min}$, while the loss modulus (G") remained unchanged. $\mathrm{G}$ ' continued to increase while irradiation lasted, reaching the plateau of $150 \pm 9 \mathrm{~Pa}$ after $60 \mathrm{~min}$. No increase in G' was observed in the control experiments after $2 \mathrm{~h}$ where either the light or photocatalyst was omitted from the rheology experiment, and only after 7 hours did G' start to increase slightly (Fig S12). We note that the relatively long irradiation times for rheology studies was due to the low intensity $\left(20 \mathrm{~mW} / \mathrm{cm}^{2}\right)$ of the rheometer light source.

For 3D encapsulation studies, LNCaP spheroids with an average diameter of $100 \mu \mathrm{m}$, prepared following our established procedure, ${ }^{91}$ were suspended in the pre-hydrogel solution. Catalase, an enzyme extensively present in humans and all organisms exposed to oxygen, was added as a co-catalyst to disproportionate the hydrogen peroxide generated by the photoreaction. Cell-laden hydrogels were created by irradiating the suspensions for $10 \mathrm{~min}$ at $180 \mathrm{~mW} / \mathrm{cm}^{2}$ in a petri dish using a custom LED far-red-light source (Fig S13). Here, relatively short irradiation times were possible by direct irradiation at high power density without any detectable cell death. The resulting hydrogel constructs were cultured and imaged at varied time points by confocal microscopy. As shown in Fig 6E, live/dead staining followed by confocal microscopy showed that the LNCaP spheroids retained excellent viability ( $>99 \%)$ throughout the cell culture experiment after 1, 7 and 14 days of culture.

The SiR-photocatalyzed tetrazine ligation was also used to create hydrogel materials in live mice by subcutaneous injection of a solution of SiR catalyst, HA-DHTz and HA-dTCO, followed by brief irradiation with $660 \mathrm{~nm}$ light source (Fig 7A). To enable in vivo imaging, a NIR chromophore Cy7 was conjugated to HA-dTCO to give Cy7-HA-dTCO (20\% dTCO and $0.5 \%$ Cy7 incorporation) (Fig 7B). A hydrogel precursor solution was then prepared by mixing HA-DHTz (2 mM), Cy7HA-dTCO $(2.5 \mathrm{mM})$, photocatalyst $1 \mathrm{~d}(40 \mu \mathrm{M})$ and catalase $(10 \mu \mathrm{M})$. This resulting solution was a free flowing, injectable liquid that was stable against background gelation even when allowed to stand in ambient light for 8 hours. However, upon irradiation for $5 \mathrm{~min}$ with $660 \mathrm{~nm}$ light $\left(530 \mathrm{~mW} / \mathrm{cm}^{2}\right)$ a hydrogel formed rapidly. The resulting hydrogel showed a $70 \%$ increase in Cy7-fluorescence at $776 \mathrm{~nm}$ relative to the non-irradiated hydrogel precursor solution (Fig 7C). This increase in fluorescence quantum yield is the expected consequence of the dramatic viscosity increase upon gelation, ${ }^{92}$ and the increase in fluorescence intensity served as a useful reporter of hydrogel formation in vivo. As shown in Fig 7D, subcutaneous injection of $0.04 \mathrm{~mL}$ of the hydrogel precursor solution in nude mice (female, 4-6 weeks old) was used to produce a fluorescent area with $\sim 6 \mathrm{~mm}$ diameter at the site of injection (Fig 7D). The fluorescence became significantly more intense upon 5 min irradiation at $660 \mathrm{~nm}$, with immediate increases in maximum $(+1.80$ fold) and total $(+1.91$-fold) radiance efficiency that were persistent over the course of 72 hours (Fig 7F, G). Complete timecourse data is presented in Fig S17. In these animals, a visible bump on the skin due to in vivo hydrogel formation became apparent after irradiation (Fig S18). Image-guided surgery was conducted $20 \mathrm{~min}$ after irradiation, and a solid, fluorescent hydrogel was readily isolated (Fig 7D and S19). In control experiments where HA-DHTz was omitted and Diels-Alder crosslinking therefore impossible, there was no initial increase in maximum fluorescence intensity (Fig 7F) upon injection, and both the maximum and total fluorescence intensity decreased significantly over the course of $72 \mathrm{~h}$. In separate controls, the hydrogel precursor solution was injected, but $660 \mathrm{~nm}$ light was not applied. Again, no increase in fluorescence intensity was observed, but the signal was persistent over $72 \mathrm{~h}$, suggesting that some gelation may have occurred. Image-guided surgery was also attempted 20 minutes post-injection. Unlike the experiment where $660 \mathrm{~nm}$ light was used, a viscoelastic solid was not formed, although a small amount of soft, sticky material was isolable (Fig S19B). Thus, some gelation took place in the dark in the in vivo environment, perhaps due to DHTz oxidation at the gel interface to form a liquid-filled sac. For an injectable material, this background gelation should provide a practical advantage by increasing viscosity and holding the shape and position of the material prior to irradiation. However, photocuring with far-red light is necessary to create a stable, cross-linked hydrogel material in vivo.

\section{Conclusions}

SiR dyes, traditionally used as biological fluorophores, have been repurposed for applications in photocatalysis. With far-red light, SiR catalyzes the activation of rapid bioorthogonal chemistry through oxidation of a dihydrotetrazine to a tetrazine. A new dihydrotetrazine/tetrazine pair with high stability in both oxidation states is described. Of the SiR dyes studied, the Janelia-SiR dyes were found to be especially effective even at low catalyst loadings (typically $1 \mu \mathrm{M}$ ) with short irradiation times. Photocatalysis is successful in the presence of trans-cyclooctene dienophiles, and photocatalytic activation of a tetrazine was demonstrated on a site-selectively modified protein without signs of oxidative damage. SiR-based photocatalysis was used to crosslink aqueous solutions of hyaluronic acid polymers that were functionalized by dihydrotetrazine and transcyclooctenes, leading to hydrogels that can support 3D-cell culture. Photocatalysis was carried out in vivo in live mice through subcutaneous injection of a solution containing SiR 
photocatalyst and a Cy7-labeled hydrogel precursor, followed by irradiation with far-red light to create stable hydrogels in vivo. We anticipate that the activation of bioorthogonal chemistry through SiR photocatalysis will serve as a valuable tool for covalent bond formation with spatio temporal control in cellular and in vivo environments.
A
subcutaneously inject
Cy7-HA-dTCO + HA-
DHTz + SiR (1d) then hv

1)

2) $660 \mathrm{~nm}$

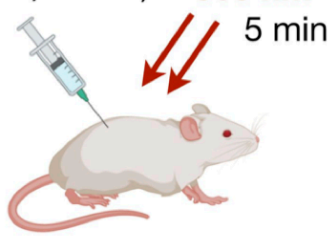

B

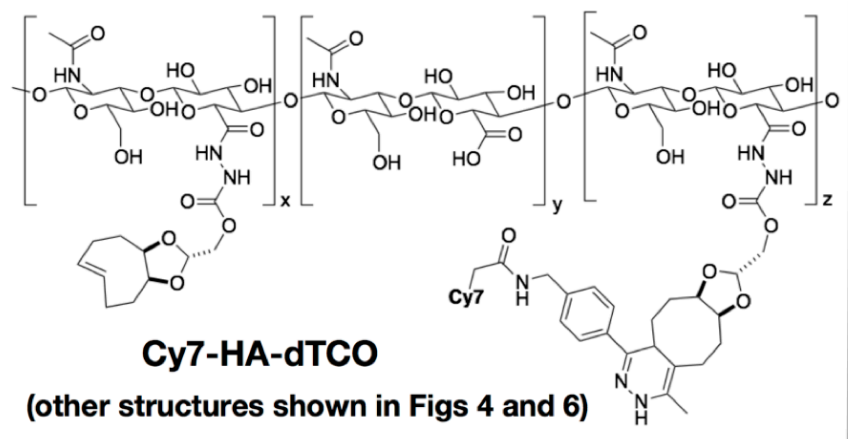

C Cy7 fluorescence intensity is higher in hydrogel

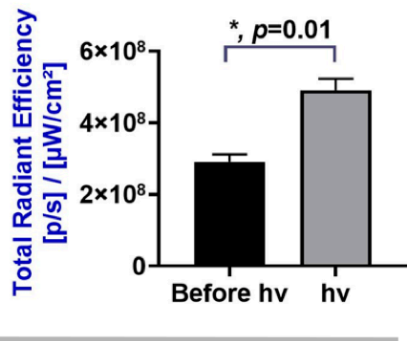

\section{In vivo hydrogel formation}
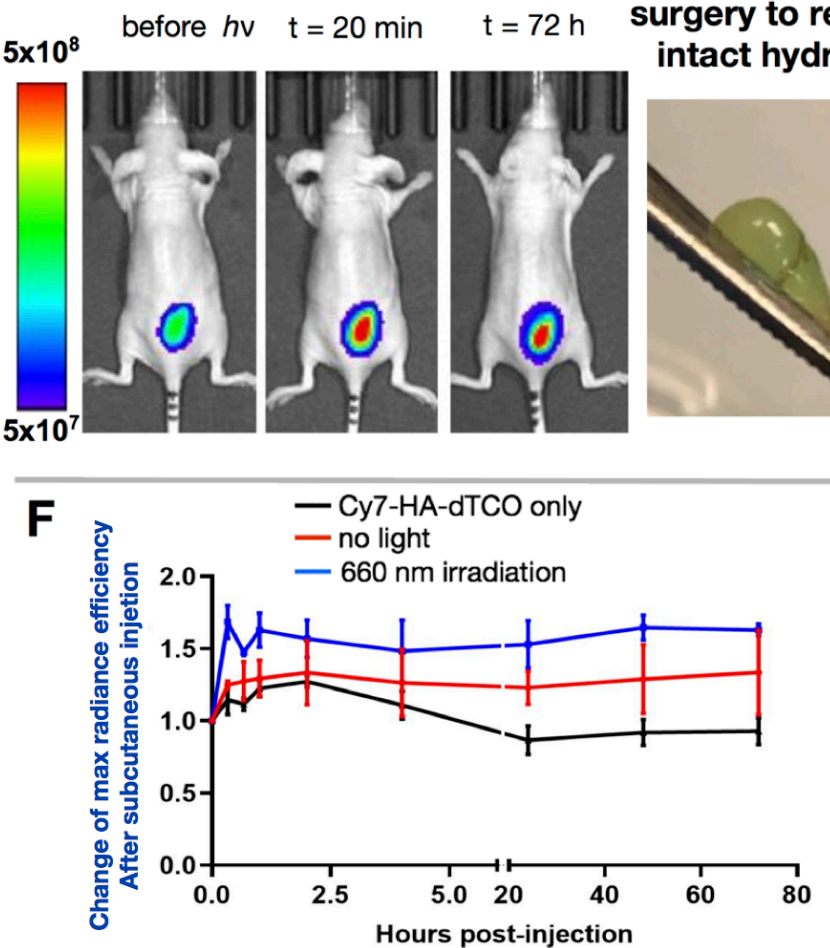

E Cy7-HA-dTCO only
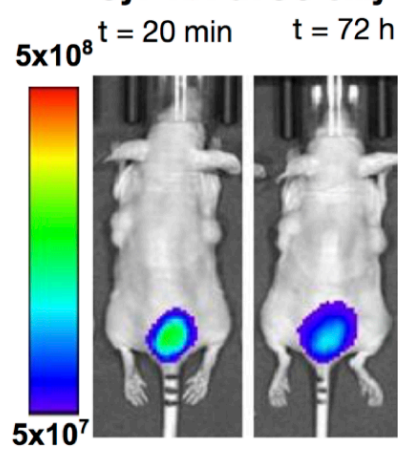

no light

$$
\mathrm{t}=20 \min \mathrm{t}=72 \mathrm{~h}
$$
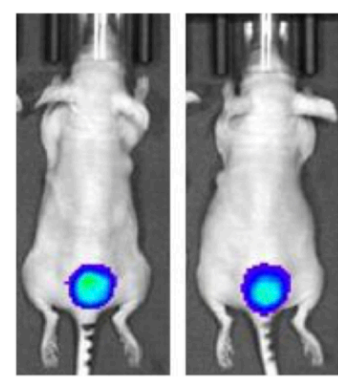

G

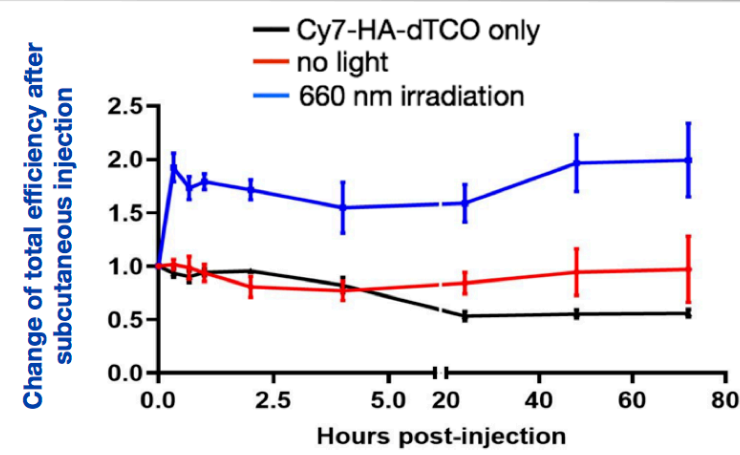

Fig 7. (A) Schematic description of procedure for injection/in vivo hydrogel formation. A solution of Cy7-HA-dTCO (2.5 mM), HA-DHTz $(2 \mathrm{mM})$, SiR catalyst $1 \mathrm{~d}(40 \mu \mathrm{M})$ and catalase $(10 \mu \mathrm{M})$ in PBS was injected subcutaneously in live mice, and then irradiated for 5 min with $660 \mathrm{~nm}$ light. (B) Structure of Cy7-HA-dTCO, prepared by the conjugation of HA-dTCO with substoichiometric Cy7-tetrazine. (C) In vitro total radiant efficiency due to Cy7 in the mixture before and after illumination by $660 \mathrm{~nm}$ light. (D) Representative time-course images of animals that were subcutaneously injected with hydrogel precursor and illuminated with $660 \mathrm{~nm}$ light. The right image shows the hydrogel that was formed in vivo and removed surgically. (E) Control experiments where Cy7-HA-dTCO was injected, and where the hydrogel precursor solution was injected without illumination. (F, G) Plots showing the change in $(\mathbf{F})$ maximum and $(\mathbf{G})$ total radiant efficiently after subcutaneous injection. 


\section{Supporting Information}

Synthetic procedures and compound characterization data; procedures for photochemical oxidation of dihydrotetrazines; procedures for protein expression, tagging and modification; 3D-cell culture protocols and photochemical hydrogelation; animal protocols and procedures for in vivo hydrogel formation.

The Supporting Information is available free of charge on the ACS Publications website. The file type is PDF.

\section{AUTHOR INFORMATION}

Corresponding Authors

*jmfox@udel.edu

*xjia@udel.edu *zibo_li@med.unc.edu

\section{Author Contributions}

$\$$ These authors contributed equally.

\section{ACKNOWLEDGMENT}

We are extremely grateful to Luke Lavis and his group for providing SiR dyes 1b-e. This work was supported by NIH (R01GM132460, R01DC014461), NSF (DMR1809612), Pfizer and the State of Delaware CAT grant program. Instrumentation was supported by NIH awards P20GM104316, P30GM110758, S10OD025185, S10OD026951 and S10OD016267.

\section{REFERENCES}

(1) Nicewicz, D. A.; Nguyen, T. M. Recent Applications of Organic Dyes as Photoredox Catalysts in Organic Synthesis. ACS Catal. 2014, 4, 355-360.

(2) Li, P.; Terrett, J. A.; Zbieg, J. R. Visible-Light Photocatalysis as an Enabling Technology for Drug Discovery: A Paradigm Shift for Chemical Reactivity. ACS Med. Chem. Lett. 2020, 11, 2120-2130.

(3) Romero, N. A.; Nicewicz, D. A. Organic Photoredox Catalysis. Chem. Rev. 2016, 116, 10075-10166.

(4) Geri, J. B.; Oakley, J. V.; Reyes-Robles, T.; Wang, T.; McCarver, S. J.; White, C. H.; Rodriguez-Rivera, F. P.; Parker, D. L.; Hett, E. C.; Fadeyi, O. O.; Oslund, R. C.; MacMillan, D. W. C. Microenvironment Mapping via Dexter Energy Transfer on Immune Cells. Science 2020, 367, 1091.

(5) Alabugin, A. Near - IR Photochemistry for Biology: Exploiting the Optical Window of Tissue. Photochem. Photobiol. 2019, $95,722-732$.

(6) Nani, R. R.; Gorka, A. P.; Nagaya, T.; Yamamoto, T.; Ivanic, J.; Kobayashi, H.; Schnermann, M. J. In Vivo Activation of Duocarmycin-Antibody Conjugates by Near-Infrared Light. ACS Cent. Sci. 2017, 3, 329-337.

(7) Palao, E.; Slanina, T.; Muchova, L.; Solomek, T.; Vitek, L.; Klan, P. Transition-Metal-Free CO-Releasing BODIPY Derivatives Activatable by Visible to NIR Light as Promising Bioactive Molecules. J. Am. Chem. Soc. 2016, 138, $126-133$.

(8) Lobo, A. C. S.; Silva, A. D.; Tomé, V. A.; Pinto, S. M. A.; Silva, E. F. F.; Calvete, M. J. F.; Gomes, C. M. F.; Pereira, M. M.; Arnaut, L. G. Phthalocyanine Labels for Near-Infrared Fluorescence Imaging of Solid Tumors. J. Med. Chem. 2016, 59, 46884696.

(9) Al-Afyouni, M. H.; Rohrabaugh, T. N.; Al-Afyouni, K. F.; Turro, C. New Ru(ii) photocages operative with near-IR light: new platform for drug delivery in the PDT window. Chemical Science 2018, 9, 6711-6720.

(10) Chilakamarthi, U.; Giribabu, L. Photodynamic Therapy: Past, Present and Future. Chem. Record 2017, 17, 775-802.

(11) Ye, S.; Cui, C.; Cheng, X.; Zhao, M.; Mao, Q.; Zhang, Y.; Wang, A.; Fang, J.; Zhao, Y.; Shi, H. Red Light-Initiated Cross-Linking of NIR Probes to Cytoplasmic RNA: An Innovative Strategy for Prolonged Imaging and Unexpected Tumor Suppression. $J$. Am. Chem. Soc. 2020, 142, 21502-21512.

(12) Devaraj, N. K. The Future of Bioorthogonal Chemistry. ACS Cent. Sci. 2018, 4, 952-959.

(13) Nguyen, S. S.; Prescher, J. A. Developing Bioorthogonal Probes to Span a Spectrum of Reactivities. Nat. Rev. 2020, 4 , 476-489.

(14) van Onzen, A. H. A. M.; Versteegen, R. M.; Hoeben, F. J. M.; Filot, I. A. W.; Rossin, R.; Zhu, T.; Wu, J.; Hudson, P. J.; Janssen, H. M.; ten Hoeve, W.; Robillard, M. S. Bioorthogonal Tetrazine Carbamate Cleavage by Highly Reactive trans-Cyclooctene. $J$. Am. Chem. Soc. 2020, 142, 10955-10963.

(15) Li, J.; Jia, S.; Chen, P. R. Diels-Alder reaction-triggered bioorthogonal protein decaging in living cells. Nat. Chem. Biol. 2014, 10, 1003-1005.

(16) Versteegen, R. M.; Rossin, R.; ten Hoeve, W.; Janssen, H. M.; Robillard, M. S. Click to Release: Instantaneous Doxorubicin Elimination upon Tetrazine Ligation. Angew. Chem. Int. Ed. 2013, 52, 14112-14116.

(17) Tu, J.; Xu, M.; Parvez, S.; Peterson, R. T.; Franzini, R. M. Bioorthogonal Removal of 3-Isocyanopropyl Groups Enables the Controlled Release of Fluorophores and Drugs in Vivo. J. Am. Chem. Soc. 2018, 140, 8410-8414.

(18) Wilkovitsch, M.; Haider, M.; Sohr, B.; Herrmann, B.; Klubnick, J.; Weissleder, R.; Carlson, J. C. T.; Mikula, H. A Cleavable C2-Symmetric trans-Cyclooctene Enables Fast and Complete Bioorthogonal Disassembly of Molecular Probes. J. Am. Chem. Soc. 2020, 142, 19132-19141.

(19) Carlson, J. C. T.; Mikula, H.; Weissleder, R. Unraveling Tetrazine-Triggered Bioorthogonal Elimination Enables Chemical Tools for Ultrafast Release and Universal Cleavage. J. Am. Chem. Soc. 2018, 140, 3603-3612.

(20) Jiménez-Moreno, E.; Guo, Z.; Oliveira, B. L.; Albuquerque, I. S.; Kitowski, A.; Guerreiro, A.; Boutureira, O.; Rodrigues, T.; Jiménez-Osés, G.; Bernardes, G. J. L. Vinyl Ether/Tetrazine Pair for the Traceless Release of Alcohols in Cells. Angew. Chem. Int. Ed. 2017, 56, 243-247.

(21) Wu, H.; Alexander, S. C.; Jin, S.; Devaraj, N. K. A Bioorthogonal Near-Infrared Fluorogenic Probe for mRNA Detection. J. Am. Chem. Soc. 2016, 138, 11429-11432. 
(22) Lelieveldt, L. P. W. M.; Eising, S.; Wijen, A.; Bonger, K. M. Vinylboronic acid-caged prodrug activation using clickto-release tetrazine ligation. Org. Biomol. Chem. 2019, 17, 8816-8821.

(23) Herner, A.; Lin, Q. Photo-Triggered Click Chemistry for Biological Applications. Top. Curr. Chem. 2015, $374,1$.

(24) Tasdelen, M. A.; Yagci, Y. Light-Induced Click Reactions. Angew. Chem. Int. Ed. 2013, 52, 5930-5938.

(25) Song, W.; Wang, Y.; Qu, J.; Madden, M. M.; Lin, Q. A photoinducible 1,3-dipolar cycloaddition reaction for rapid, selective modification of tetrazole-containing proteins. Angew. Chem. Int. Ed. 2008, 47, 2832-2835.

(26) An, P.; Lewandowski, T. M.; Erbay, T. G.; Liu, P.; Lin, Q. Sterically Shielded, Stabilized Nitrile Imine for Rapid Bioorthogonal Protein Labeling in Live Cells. J. Am. Chem. Soc. 2018, 140, 4860-4868.

(27) Yu, Z.; Lin, Q. Design of Spiro[2.3]hex-1-ene, a Genetically Encodable Double-Strained Alkene for Superfast Photoclick Chemistry. J. Am. Chem. Soc. 2014, 136, 4153-4156.

(28) Mayer, S. V.; Murnauer, A.; Wrisberg, M. K.; Jokisch, M. L.; Lang, K. Photo - induced and Rapid Labeling of Tetrazine - Bearing Proteins via Cyclopropenone - Caged Bicyclononynes. Angew. Chem. Int. Ed. 2019, 58, $15876-15882$.

(29) Mcnitt, C. D.; Cheng, H.; Ullrich, S.; Popik, V. V.; Bjerknes, M. Multiphoton Activation of Photo-Strain-Promoted Azide Alkyne Cycloaddition "Click" Reagents Enables in Situ Labeling with Submicrometer Resolution. J. Am. Chem. Soc. 2017, 139, 14029-14032.

(30) Poloukhtine, A. A.; Mbua, N. E.; Wolfert, M. A.; Boons, G. J.; Popik, V. V. Selective labeling of living cells by a photo-triggered click reaction. J. Am. Chem. Soc. 2009, 131, 15769-15776.

(31) Sutton, D. A.; Popik, V. V. Sequential Photochemistry of Dibenzo[a,e]dicyclopropa[c,g][8]annulene-1,6-dione: Selective Formation of Didehydrodibenzo[a,e][8]annulenes with Ultrafast SPAAC Reactivity. J. Org. Chem. 2016, 81, 8850-8857.

(32) Shah, L.; Laughlin, S. T.; Carrico, I. S. Light-Activated Staudinger-Bertozzi Ligation within Living Animals. J. Am. Chem. Soc. 2016, 138, 5186-5189.

(33) Shete, A. U.; El-Zaatari, B. M.; French, J. M.; Kloxin, C. J. Blue-light activated rapid polymerization for defect-free bulk $\mathrm{Cu}(\mathrm{i})$-catalyzed azide-alkyne cycloaddition (CuAAC) crosslinked networks. Chem. Commun. 2016, 52, 10574-10577.

(34) Lim, R. K. V.; Lin, Q. Azirine ligation: fast and selective protein conjugation via photoinduced azirine-alkene cycloaddition. Chem. Commun. 2010, 46, 7993-7995.

(35) Gann, A. W.; Amoroso, J. W.; Einck, V. J.; Rice, W. P.; Chambers, J. J.; Schnarr, N. A. A photoinduced, benzyne click reaction. Org. Lett. 2014, 16, 2003-2005.

(36) Gao, J.; Xiong, Q.; Wu, X.; Deng, J.; Zhang, X.; Zhao, X.; Deng, P.; Yu, Z. Direct ring-strain loading for visible-light accelerated bioorthogonal ligation via diarylsydnone-dibenzo[b,f][1,4,5]thiadiazepine photo-click reactions. Commun. Chem. 2020, 29.

(37) Zhang, L.; Zhang, X.; Yao, Z.; Jiang, S.; Deng, J.; Li, B.; Yu, Z. Discovery of Fluorogenic Diarylsydnone-Alkene Photoligation: Conversion of ortho-Dual-Twisted Diarylsydnones into Planar Pyrazolines. J. Am. Chem. Soc. 2018, 140, $7390-7394$.

(38) Li, J.; Kong, H.; Huang, L.; Cheng, B.; Qin, K.; Zheng, M.; Yan, Z.; Zhang, Y. Visible Light-Initiated Bioorthogonal Photoclick Cycloaddition. J Am Chem Soc 2018, 140, 14542-14546.

(39) Li, J.; Kong, H.; Zhu, C.; Zhang, Y. Photo-controllable bioorthogonal chemistry for spatiotemporal control of biotargets in living systems. Chem. Sci. 2020, 11, 3390-3396.

(40) Bruins, J. J.; Albada, B.; van Delft, F. ortho-Quinones and Analogues Thereof: Highly Reactive Intermediates for Fast and Selective Biofunctionalization. Chem. Eur. J. 2018, 24, 4749-4756.

(41) Bruins, J. J.; Blanco-Ania, D.; Van Der Doef, V.; Van Delft, F. L.; Albada, B. Orthogonal, dual protein labelling by tandem cycloaddition of strained alkenes and alkynes to ortho-quinones and azides. Chem. Commun. 2018, 54, 7338-7341.

(42) Arumugam, S.; Popik, V. V. Photochemical Generation and the Reactivity ofo-Naphthoquinone Methides in Aqueous Solutions. J. Am. Chem. Soc. 2009, 131, 11892-11899.

(43) Feist, F.; Rodrigues, L. L.; Walden, S. L.; Krappitz, T. W.; Dargaville, T. R.; Weil, T.; Goldmann, A. S.; Blinco, J. P.; Barner-Kowollik, C. Light-induced Ligation of o-Quinodimethanes with Gated Fluorescence Self-reporting. J. Am. Chem. Soc. 2020, 142, 7744-7748.

(44) Bruins, J. J.; Westphal, A. H.; Albada, B.; Wagner, K.; Bartels, L.; Spits, H.; Van Berkel, W. J. H.; Van Delft, F. L. Inducible, Site-Specific Protein Labeling by Tyrosine Oxidation-Strain-Promoted (4 2) Cycloaddition. Bioconj. Chem. 2017, 28, 11891193.

(45) Singh, K.; Fennell, C. J.; Coutsias, E. A.; Latifi, R.; Hartson, S.; Weaver, J. D. Light Harvesting for Rapid and Selective Reactions: Click Chemistry with Strain-Loadable Alkenes. Chem 2018, 4, 124-137.

(46) Yu, Z.; Ohulchanskyy, T. Y.; An, P.; Prasad, P. N.; Lin, Q. Fluorogenic, Two-Photon-Triggered Photoclick Chemistry in Live Mammalian Cells. J. Am. Chem. Soc. 2013, 135, 16766-16769.

(47) Zhang, H.; Trout, W. S.; Liu, S.; Andrade, G. A.; Hudson, D. A.; Scinto, S. L.; Dicker, K. T.; Li, Y.; Lazouski, N.; Rosenthal, J.; Thorpe, C.; Jia, X.; Fox, J. M. Rapid Bioorthogonal Chemistry Turn-on through Enzymatic or Long Wavelength Photocatalytic Activation of Tetrazine Ligation. J. Am. Chem. Soc. 2016, 138, 5978-5983.

(48) Darko, A.; Wallace, S.; Dmitrenko, O.; Machovina, M. M.; Mehl, R. A.; Chin, J. W.; Fox, J. M. Conformationally Strained trans-Cyclooctene with Improved Stability and Excellent Reactivity in Tetrazine Ligation. Chem. Sci. 2014, 5, 3770-3776.

(49) Selvaraj, R.; Fox, J. M. trans-Cyclooctene--a stable, voracious dienophile for bioorthogonal labeling. Curr. Opin. Chem. Biol. 2013, 17, 753-760.

(50) Wu, H.; Devaraj, N. K. Inverse Electron-Demand Diels-Alder Bioorthogonal Reactions. Top. Curr. Chem. 2016, 374 ,

3.

(51) Wu, H.; Devaraj, N. K. Advances in Tetrazine Bioorthogonal Chemistry Driven by the Synthesis of Novel Tetrazines and Dienophiles. Acc Chem Res 2018, 51, 1249-1259.

(52) Kumar, P.; Zainul, O.; Camarda, F. M.; Jiang, T.; Mannone, J. A.; Huang, W.; Laughlin, S. T. Caged Cyclopropenes with Improved Tetrazine Ligation Kinetics. Org. Lett. 2019, 21, 3721-3725. 
(53) Jiang, T.; Kumar, P.; Huang, W.; Kao, W. S.; Thompson, A. O.; Camarda, F. M.; Laughlin, S. T. Modular Enzyme and Light - Based Activation of Cyclopropene-Tetrazine Ligation. ChemBioChem 2019, 20, 2222-2226.

(54) Selvaraj, R.; Fox, J. M. An efficient and mild oxidant for the synthesis of s-tetrazines. Tetrahedron Lett. 2014, 55, 4795-4797.

(55) Ehret, F.; Wu, H.; Alexander, S. C.; Devaraj, N. K. Electrochemical Control of Rapid Bioorthogonal Tetrazine Ligations for Selective Functionalization of Microelectrodes. J. Am. Chem. Soc. 2015, 137, 8876-8879.

(56) Min, D. J.; Miomandre, F.; Audebert, P.; Kwon, J. E.; Park, S. Y. s-Tetrazines as a New Electrode-Active Material for Secondary Batteries. ChemSusChem 2019, 12, 503-510.

(57) Nickerl, G.; Senkovska, I.; Kaskel, S. Tetrazine functionalized zirconium MOF as an optical sensor for oxidizing gases. Chem. Commun. 2015, 51, 2280-2282.

(58) Liu, L.; Zhang, D.; Johnson, M.; Devaraj, N. K. Light-activated tetrazines enable live-cell spatiotemporal control of bioorthogonal reactions. bioRxiv 2020, 2020.2012.2001.405423.

(59) Haines, L. A.; Rajagopal, K.; Ozbas, B.; Salick, D. A.; Pochan, D. J.; Schneider, J. P. Light-Activated Hydrogel Formation via the Triggered Folding and Self-Assembly of a Designed Peptide. J. Am. Chem. Soc. 2005, 127, $17025-17029$.

(60) Arkenberg, M. R.; Nguyen, H. D.; Lin, C.-C. Recent advances in bio-orthogonal and dynamic crosslinking of biomimetic hydrogels. J. Mater. Chem. B. 2020, 8, 7835-7855.

(61) Prestwich, G. D. Hyaluronic acid-based clinical biomaterials derived for cell and molecule delivery in regenerative medicine. J. Control. Release 2011, 155, 193-199.

(62) Wu, H.-D.; Yang, J.-C.; Tsai, T.; Ji, D.-Y.; Chang, W.-J.; Chen, C.-C.; Lee, S.-Y. Development of a chitosanpolyglutamate based injectable polyelectrolyte complex scaffold. Carbohydrate Polymers 2011, 85, 318-324.

(63) Xu, Q.; Guo, L.; A, S.; Gao, Y.; Zhou, D.; Greiser, U.; Creagh-Flynn, J.; Zhang, H.; Dong, Y.; Cutlar, L.; Wang, F.; Liu, W.; Wang, W.; Wang, W. Injectable hyperbranched poly(beta-amino ester) hydrogels with on-demand degradation profiles to match wound healing processes. Chem. Sci. 2018, 9, 2179-2187.

(64) DeForest, C. A.; Polizzotti, B. D.; Anseth, K. S. Sequential click reactions for synthesizing and patterning threedimensional cell microenvironments. Nat. Mater. 2009, 8, 659-664.

(65) Skardal, A.; Murphy, S. V.; Crowell, K.; Mack, D.; Atala, A.; Soker, S. A tunable hydrogel system for long-term release of cell-secreted cytokines and bioprinted in situ wound cell delivery. J. Biomed. Mater. Res. B Appl. Biomater. 2017, 105, 19862000 .

(66) Lim, K. S.; Klotz, B. J.; Lindberg, G. C. J.; Melchels, F. P. W.; Hooper, G. J.; Malda, J.; Gawlitta, D.; Woodfield, T. B. F. Visible Light Cross-Linking of Gelatin Hydrogels Offers an Enhanced Cell Microenvironment with Improved Light Penetration Depth. Macromol. Biosci. 2019, 19, e1900098.

(67) Meng, Z.; Zhou, X.; Xu, J.; Han, X.; Dong, Z.; Wang, H.; Zhang, Y.; She, J.; Xu, L.; Wang, C.; Liu, Z. LightTriggered In Situ Gelation to Enable Robust Photodynamic-Immunotherapy by Repeated Stimulations. Adv. Mater. 2019,31 , e1900927.

(68) Brown, T. E.; Anseth, K. S. Spatiotemporal hydrogel biomaterials for regenerative medicine. Chem. Soc. Rev. 2017,

$46,6532-6552$.

(69) Xu, X.; Farach-Carson, M. C.; Jia, X. Three-dimensional in vitro tumor models for cancer research and drug evaluation. Biotechnol. Adv. 2014, 32, 1256-1268.

(70) Xu, X.; Sabanayagam, C. R.; Harrington, D. A.; Farach-Carson, M. C.; Jia, X. A hydrogel-based tumor model for the evaluation of nanoparticle-based cancer therapeutics. Biomat. 2014, 35, 3319-3330.

(71) Ding, J.; Yao, Y.; Li, J.; Duan, Y.; Nakkala, J. R.; Feng, X.; Cao, W.; Wang, Y.; Hong, L.; Shen, L.; Mao, Z.; Zhu, Y.; Gao, C. A Reactive Oxygen Species Scavenging and O2 Generating Injectable Hydrogel for Myocardial Infarction Treatment In vivo. Small 2020, 16, 2005038.

(72) Cui, L.; Vivona, S.; Smith, B. R.; Kothapalli, S.-R.; Liu, J.; Ma, X.; Chen, Z.; Taylor, M.; Kierstead, P. H.; Fréchet, J. M. J.; Gambhir, S. S.; Rao, J. Reduction Triggered In Situ Polymerization in Living Mice. J. Am. Chem. Soc. 2020, 142, $15575-15584$.

(73) Boase, N. R. B. Shining a Light on Bioorthogonal Photochemistry for Polymer Science. Macromol. Rap. Commun. 2020, 41, 2000305.

(74) Carthew, J.; Frith, J. E.; Forsythe, J. S.; Truong, V. X. Polyethylene glycol-gelatin hydrogels with tuneable stiffness prepared by horseradish peroxidase-activated tetrazine-norbornene ligation. J. Mater. Chem. B. 2018, 6, 1394-1401.

(75) Truong, V. X.; Tsang, K. M.; Ercole, F.; Forsythe, J. S. Red Light Activation of Tetrazine-Norbornene Conjugation for Bioorthogonal Polymer Cross-Linking across Tissue. Chem. Mat. 2017, 29, 3678-3685.

(76) Liu, Z.; Lv, Y.; Zhu, A.; An, Z. One-Enzyme Triple Catalysis: Employing the Promiscuity of Horseradish Peroxidase for Synthesis and Functionalization of Well-Defined Polymers. ACS Macro Lett. 2018, 7, 1-6.

(77) Fu, M.; Xiao, Y.; Qian, X.; Zhao, D.; Xu, Y. A design concept of long-wavelength fluorescent analogs of rhodamine dyes: replacement of oxygen with silicon atom. Chem. Commun. 2008, 1780-1782.

(78) Koide, Y.; Urano, Y.; Hanaoka, K.; Terai, T.; Nagano, T. Evolution of Group 14 Rhodamines as Platforms for NearInfrared Fluorescence Probes Utilizing Photoinduced Electron Transfer. ACS Chem. Biol. 2011, 6, 600-608.

(79) Koide, Y.; Urano, Y.; Hanaoka, K.; Piao, W.; Kusakabe, M.; Saito, N.; Terai, T.; Okabe, T.; Nagano, T. Development of NIR Fluorescent Dyes Based on Si-rhodamine for in Vivo Imaging. J. Am. Chem. Soc. 2012, 134, 5029-5031.

(80) Grimm, J. B.; Brown, T. A.; Tkachuk, A. N.; Lavis, L. D. General Synthetic Method for Si-Fluoresceins and SiRhodamines. ACS Cent. Sci. 2017, 3, 975-985.

(81) Kim, S.; Tachikawa, T.; Fujitsuka, M.; Majima, T. Far-Red Fluorescence Probe for Monitoring Singlet Oxygen during Photodynamic Therapy. J. Am. Chem. Soc. 2014, 136, 11707-11715.

(82) To remove adventitous metal impurities, PBS buffer was purified by filtration through chelex resin prior to use.

(83) Devasagayam, T. P. A.; Sundquist, A. R.; Di Mascio, P.; Kaiser, S.; Sies, H. Activity of thiols as singlet molecular oxygen quenchers. J. Photochem. Photobiol. B 1991, 9, 105-116. 
(84) Lincoln, R.; Greene, L. E.; Krumova, K.; Ding, Z.; Cosa, G. Electronic Excited State Redox Properties for BODIPY Dyes Predicted from Hammett Constants: Estimating the Driving Force of Photoinduced Electron Transfer. J. Phys. Chem. A. 2014, 118, 10622-10630.

(85) Heinlein, T.; Knemeyer, J.-P.; Piestert, O.; Sauer, M. Photoinduced Electron Transfer between Fluorescent Dyes and Guanosine Residues in DNA-Hairpins. J. Phys. Chem. B. 2003, 107, 7957-7964.

(86) Taylor, M. T.; Blackman, M. L.; Dmitrenko, O.; Fox, J. M. Design and synthesis of highly reactive dienophiles for the tetrazine-trans-cyclooctene ligation. J. Am. Chem. Soc. 2011, 133, 9646-9649.

(87) Koshy, S. T.; Desai, R. M.; Joly, P.; Li, J.; Bagrodia, R. K.; Lewin, S. A.; Joshi, N. S.; Mooney, D. J. ClickCrosslinked Injectable Gelatin Hydrogels. Adv. Healthc. Mater. 2016, 5, 541-547.

(88) Dicker, K. T.; Moore, A. C.; Garabedian, N. T.; Zhang, H.; Scinto, S. L.; Akins, R. E.; Burris, D. L.; Fox, J. M.; Jia, X. Spatial Patterning of Molecular Cues and Vascular Cells in Fully Integrated Hydrogel Channels via Interfacial Bioorthogonal CrossLinking. ACS Appl. Mater. Interf. 2019, 11, 16402-16411.

(89) Ozdemir, T.; Fowler, E. W.; Liu, S.; Harrington, D. A.; Witt, R. L.; Farach-Carson, M. C.; Pradhan-Bhatt, S.; Jia, X. Tuning Hydrogel Properties to Promote the Assembly of Salivary Gland Spheroids in 3D. ACS Biomater. Sci. Eng. 2016, 2, $2217-2230$.

(90) Zhang, H.; Dicker, K. T.; Xu, X.; Jia, X.; Fox, J. M. Interfacial Bioorthogonal Cross-Linking. ACS Macro Lett. 2014, $3,727-731$.

(91) Ozdemir, T.; Srinivasan, P. P.; Zakheim, D. R.; Harrington, D. A.; Witt, R. L.; Farach-Carson, M. C.; Jia, X.; PradhanBhatt, S. Bottom-up assembly of salivary gland microtissues for assessing myoepithelial cell function. Biomaterials 2017, 142, $124-135$.

(92) Sharafy, S.; Muszkat, K. A. Viscosity dependence of fluorescence quantum yields. J. Am. Chem. Soc. 1971, 93, 41194125 . 


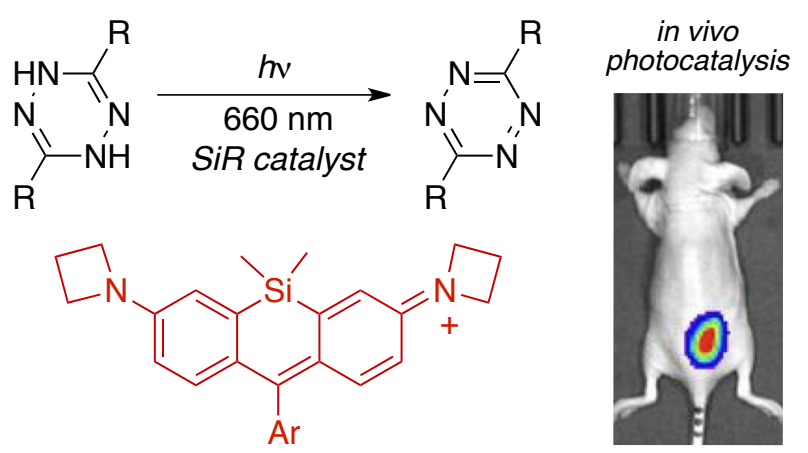

